\section{Contemporary obturation of the root canal system}

\author{
R. M. E. Tomson, ${ }^{* 1}$ N. Polycarpou ${ }^{1}$ and P. L. Tomson ${ }^{2}$
}

IN BRIEF
Explains the rationale behind obturation
and when to obturate.
Provides an overview of contemporary
obturation materials and techniques.
Presents the factors of obturation
that effect the outcome of root canal
treatment.

This article will provide an overview of the rationale behind taking a contemporary approach to obturation of the root canal system. It will outline a broad range of obturation materials including those traditionally used and newer, advanced ones that are now available that have active physical and biological properties. Obturation techniques will be described in detail, including advice for those difficult cases such as managing obturation of a canal with a wide open apex. Assessment of obturation will also be discussed, considering those factors which affect outcome of root canal treatment.

\section{INTRODUCTION}

The ultimate biologic aim of root canal treatment is the prevention or cure of apical periodontitis. When the pulp is rendered non-viable, root canal treatment attempts to fulfil its aim by debridement, disinfection and obturation of the root canal system. Since the seminal research by Kakehashi in 1965, the role of microorganisms and their by-products has been demonstrated countless times as the main causative factor in the aetiology of apical periodontitis. ${ }^{1}$ The elimination of microorganisms and their by-products is, therefore, the key to success. The removal of microorganisms is primarily achieved during the debridement and disinfection stages of treatment., ${ }^{2,3}$ The obturation stage is carried out to fill the root canal ${ }^{4}$ in an attempt to provide a hermetic seal from the coronal orifice of the canal to the apical foramen at the cementodentinal junction. However, it is important to recognise that the responsibility does not end here; the coronal seal forms an integral part of endodontic treatment and therefore plays a vital role in the treatment's success. ${ }^{5}$

${ }^{1}$ Consultant and Specialist in Endodontics, King's College Hospital NHS Foundation Trust, King's College Dental Hospital, Bessemer Road, London, SE5 9RS, UK; ${ }^{2}$ Clinical Lecturer and Honorary Consultant in Restorative Dentistry; The University of Birmingham College of Medical and Dental Sciences, School of Dentistry,

St Chad's Queensway, Birmingham, B4 6NN

${ }^{*}$ Correspondence to: Rachel M. E. Tomson

Email: racheltomson@nhs.net

Refereed Paper

Accepted 23 January 2014

DOI: 10.1038/sj.bdj.2014.205

${ }^{\circledR}$ British Dental Journal 2014; 216: 315-322

\section{RATIONALE OF OBTURATION}

The aim of obturation is to establish a fluidtight barrier with the aim of protecting the periradicular tissues from microorganisms that reside in the oral cavity. While a perfect airtight or hermatic seal is unachievable in reality, every effort should be made to reach this target. The establishment of a well obturated system would serve three main functions: ${ }^{6}$

1. Prevent coronal leakage of microorganisms or potential nutrients to support their growth into the dead space of the root canal system

2. Prevent periapical or periodontal fluids percolating into the root canals and feeding microorganisms

3. Entomb any residual microorganisms that have survived the debridement and disinfection stages of treatment, in order to prevent their proliferation and pathogenicity.

The timing involved with obturation raises the issue of single versus multiple visit treatment. Obturation should only be carried out following thorough chemo-mechanical debridement of the root canal system ${ }^{7}$ and, if the root canal system is dry and time permits, obturating at the same visit is recommended. ${ }^{8}$ However, if one cannot achieve a dry root canal system that is free from blood or exudate, then the suggested course of action would be to dress the tooth with an inter-appointment dressing. While the use of EDTA has been recommended for the removal of the smear layer formed during debridement of the root canal ${ }^{9}$ there is no existing evidence to support its use in primary root canal treatment. Interestingly, however, its use in retreatment cases has been shown to have a positive effect on treatment outcome. ${ }^{10}$

It has been demonstrated that, no matter how successfully obturation is carried out, root canals lacking a satisfactory coronal seal will leak within a short time of completion. ${ }^{11}$ This suggests that the provision of a suitable coronal seal at the earliest possible opportunity decreases the risk of coronal leakage. The quality of this seal is of paramount importance as it has been shown that treatment outcomes can be significantly affected, ${ }^{12}$ with better healing rates exhibited in teeth with satisfactory restorations. In cases where posterior teeth have lost a marginal ridge, cuspal coverage restorations are recommended; this is carried out in order to prevent fracture ${ }^{13}$ and thereby increases the possibility of tooth survival. ${ }^{14}$ The use of a sub-seal beneath the core has been suggested as an additional option for minimising coronal leakage. ${ }^{15,16}$ This subseal material should cover the orifices of the canal and the floor of the pulp chamber in multi-rooted teeth. ${ }^{15}$ Various materials have been recommended for this application such as polymethylmethacrylate reinforced zinc oxide eugenol cement (Intermediate restorative material [Dentsply Caulk, Milford, USA]) and glass ionomer cement.

\section{CURRENT MATERIALS FOR OBTURATION}

The materials most commonly used for obturation are a combination of semisolid cores and a cement, though various newer two-part semi-solid core and cement systems are also available. Calcium silicate cements are commonly used when managing 
a wide-open apex as they offer the most suitable material properties for this clinical situation. The ideal properties of a root filling material remain as suggested by Grossman in $1978 .{ }^{17}$ However, at present no material can satisfy all of these demands.

Ideal properties of a root filling material:

- Easy handling and ample working time

- Seal the canal laterally and apically conforming to the complex internal anatomy

- Dimensionally stable

- Non-irritant

- Does not stain the tooth structure

- Antimicrobial

- Impervious and non-porous

- Unaffected by tissue fluid

- Radiopaque

- Easily removed.

An additional demand, suitable for today's biological age, would be for the material to actively induce regeneration of the periradicular tissues.

\section{Gutta percha}

Gutta percha (GP) is the most commonly used root filling material, it is a naturally occurring rubber with the chemical name trans-1,4-polyisoprene. GP in a traditional form contains zinc oxide (65\%), gutta percha (20\%), radio opacifier (metal sulphate) (10\%) and plasticiser (5\%) (percentages in brackets are an approximation and will depend upon the manufacturer). ${ }^{18} \mathrm{GP}$ principally occurs in two crystalline forms; alpha and beta phases. GP cones or points are produced in the beta phase. When heated to between $42-49^{\circ} \mathrm{C}$ it will be converted to the alpha phase and beyond these temperatures it will become amorphous. Upon cooling it will return to the beta phase and will contract while doing so.

GP is offered in both cone and pellet forms. Cones are available in a range of different sizes, which include: ISO standardised 0.02 taper (Fig. 1) and nonstandardised in 0.04, 0.06, 0.08, 0.10, 0.12 taper with feathered or specified tip sizes. Non-standardised cones are also available to match various preparation systems such as Protaper (Dentsply Maillefer, Ballaigues, Switzerland) Recripoc (VDW Zentrale, München, Germany) Waveone (Dentsply Maillefer, Ballaigues, Switzerland), and System Greater Taper (GT) (Dentsply Maillefer, Ballaigues, Switzerland) (Fig. 2). The accessory points from various manufacturers are sized differently and have specific matched spreaders, for example A, B, C and D system (Dentsply Maillefer, Ballaigues, Switzerland) (Fig. 3) and Sybron Endo system XF, FF, MF, F, FM and M (Sybronendo, Orange, USA). Some GP systems are coated with resin and/or glass ionomer. It is important that these are used with the recommended sealer.

\section{Calcium silicate cements}

Calcium silicate cements are a group of materials that have evolved from mineral trioxide aggregate (MTA) and are used for obturating the root canal system in cases where the material interface with the periradicular tissues is larger than normal. Indications for the use of such materials include obturation of wide open apices, root perforations and root end fillings. MTA was developed in the 1990s by Mahmoud Torabinejad ${ }^{19}$ and given approval by the US Food and Drugs Administration (FDA) in 1998 as ProRoot MTA Original (Dentsply Tulsa Dental, Oklahoma, USA). It is presented as a powder, which is mixed with water, at a specific powder to water ratio to obtain a workable 'sandy' consistency. The composition is predominantly based on ordinary Portland cement (OPC) with additives such as calcium sulphate to improve handling and bismuth oxide to make it radiopaque. Since its introduction, MTA has undergone extensive research as a clinical material that interfaces with the pulpal and periradicular tissues and subsequently, it has been described as 'one of the least cytotoxic dental materials commercially available'. ${ }^{20}$ Although the biocompatibility of MTA has been clearly demonstrated the biological mechanism with which it induces such a favourable tissue response is poorly understood. The surface of MTA has been reported to form hydroxyapatite when it is in contact with synthetic body fluids..$^{21,22,23}$ It is suggested that this biologically accepted surface layer allows for excellent cell/material adhesion and enables superior sealing characteristics when compared with other materials. When in contact with dentine the soluble products of white and grey MTA have been shown to release growth factors that may initiate favourable healing of pulpal and periradicular tissues. ${ }^{24,25}$ Having grown in popularity, MTA has spurred similar materials to be developed by competing manufacturers. MTA Angelus (Angelus Soluções Odontológicas, Londrina, Brazil) is a more affordable alternative that has recently come in grey and white forms; it does not contain calcium sulphate, ${ }^{26,27}$ which may explain its shorter setting time of 10-15 minutes. ${ }^{28,29}$ As ProRoot MTA and MTA Angelus are based on OPC and thus manufactured from naturally occurring raw materials, it is conceivable that they contain traces of heavy metals such as arsenic, lead and chromium. ${ }^{27,30,31}$ In an attempt to prevent this contamination other manufacturers use pure laboratory grade materials such

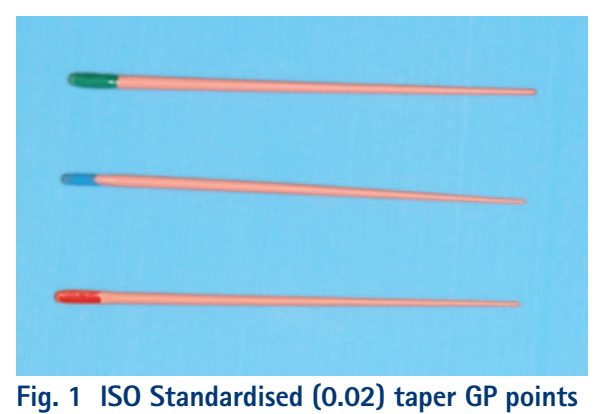

Fig. 1 ISO Standardised (0.02) taper GP points

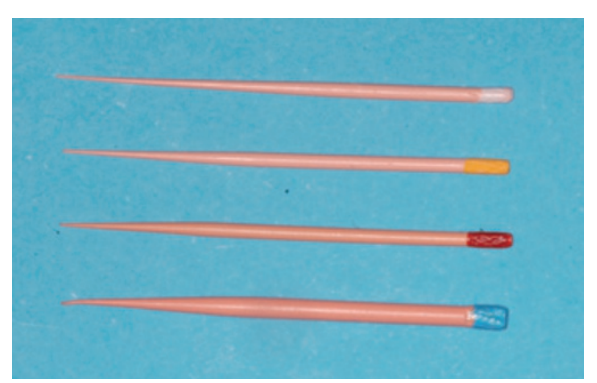

Fig. 2 System GT GP; Tapers 0.06, 0.08, $0.10,0.12$

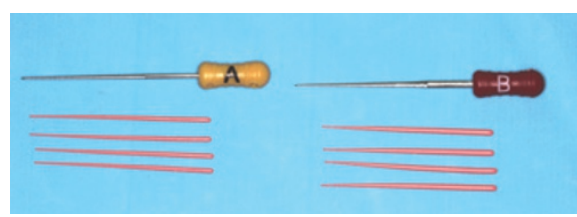

Fig. 3 Size A and B spreaders with matching accessory GP points (Dentsply)

as Bioaggregate (Innovative Bioceramix Inc. Vancouver, Canada) and Biodentine (Septodont, Saint Maur des Fosses, France). Bioaggregate is composed predominantly of calcium silicate oxide and calcium silicate. Hydroxyapatite, calcium phosphate silicate and calcite are also present, with tantalum oxide used as the radiopacifier. ${ }^{32}$ Biodentine powder predominantly consists of tri-calcium silicate as the core material with di-calcium silicate, calcium carbonate (filler), iron oxide (shade) and zirconium oxide (radiopacifier). Due to its faster setting time and better mechanical properties Biodentine also can be used as a bulk restorative material for direct and indirect pulp capping. ${ }^{33}$ However, when it is used as an obturation material in the root and root trunk it has a huge disadvantage of having a similar radiopacity to dentine; therefore if viewed on a radiograph it cannot be clearly distinguished as an iatrogenic intervention.

\section{Sealers}

Used in combination with a core material, sealers have been shown to have a positive influence on the outcome of root canal treatment. ${ }^{34}$

Their role is to:

- Seal the space between the obturating core material and the internal root surface 


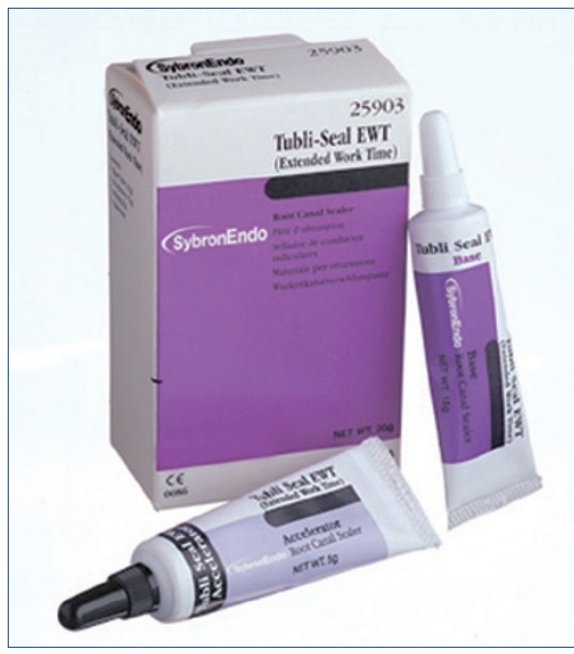

Fig. 4 Tubliseal EWT sealer

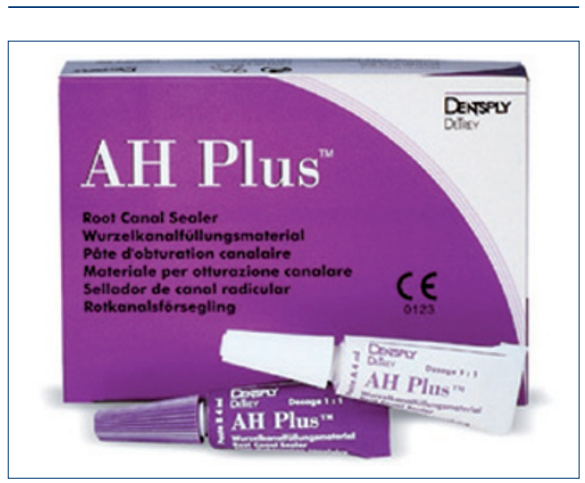

Fig. $5 \mathrm{AH}$ plus sealer

- Fill the space between core and accessory filling materials in lateral condensation

- Seal the irregularities of the complex canal anatomy for example, lateral canals and tubules

- Lubricate and facilitate seating of the core and accessory filling material

- Deliver antibacterial properties to the obturation system.

Grossman $^{35}$ listed the ideal properties of endodontic sealers as:

- Establish a hermetic seal

- Dimensionally stable on setting; expansion may be desirable

- Does not cause discolouration of the tooth

- Exhibits a slow setting time

- Insolubility in tissue fluids

- Anti-microbial

- Non-irritant

- Exhibits tackiness when mixed, to allowing suitable adhesion between it and the canal wall when set

- A fine powder so as to be easily mixable with a liquid and soluble when in contact with a common solvent if removal the root canal filling is necessary.

As this type of material will interact with the periradicular tissues, our modern expectations are greater than Grossman's, which simply demanded for it to be a nonirritant. The capacity now exists for such materials not only to be biocompatible, but promote regeneration of tissues following disease.

\section{Types of sealers}

Sealers can be broadly categorised into the following groups:

- Zinc oxide eugenol-based

- Calcium hydroxide-based

- Glass ionomer-based

- Resin-based

- Calcium silicate-based

- Silicone-based.

Outlined below are the key properties for each material.

Zinc oxide eugenol-based:

This group of materials is perhaps the most commonly used and have an established track record in obturation of the root canal. ${ }^{35}$ The materials are produced in two forms: powder liquid form, for example Roth Root Canal Cement (Roth International Ltd, Chicago, USA) or a two-paste preparation, for example Tubliseal (Kerr, Orange, USA). It is important from an endodontic perspective to note that these sealers are antimicrobial. ${ }^{36}$ The powder liquid preparations set very slowly, ${ }^{37}$ which can cause transient irritation..$^{38}$ To combat this issue extended working time pastes such as Tubliseal EWT (SybroEndo, Orange, USA) (Fig. 4) have been developed; they are designed for use with heat carriers. Zinc oxide eugenol materials resorb if extruded into the periapical tissues, ${ }^{39}$ shrink slightly on setting ${ }^{40}$ and are slightly soluble. ${ }^{41}$

Calcium hydroxide-based:

Being antibacterial, calcium hydroxide presents as a seemingly welcome component of a root canal sealer for example, Sealapex (SybroEndo, Orange, USA), Apexit (Ivoclar Vivadent, Schaan, Liechtenstein). However, the fact that calcium hydroxide's antimicrobial properties are dependent on its dissolution renders its efficacy slightly counterproductive. ${ }^{42}$ These cements have been shown to be less antimicrobial than zinc oxide-based sealers though also slightly less toxic. ${ }^{43}$

Glass ionomer-based:

Although they adhere to dentine, ${ }^{44}$ glass ionomer-based sealers have been shown to be more soluble and exhibit less antimicrobial activity than both zinc oxide eugenol and calcium hydroxide-based sealers. ${ }^{45}$ They can also be more difficult to remove for any correction or retreatment. Ketac-Endo (3M
United Kingdom plc, Bracknell, UK) is an example of such a sealer.

Resin-based:

AHPlus (Dentsply DeTrey GmbH, Kronstanz, Germany) (Fig. 5) is a resin-based sealer, which unlike its predecessor, AH26 (Dentsply DeTrey GmbH, Kronstanz, Germany), does not release formaldehyde. It does have superior sealing ability, adheres to dentine and is antimicrobial. ${ }^{46}$ If extruded into the periapical tissues, AHPlus does not resorb easily and can produce an inflammatory response, however, it becomes well tolerated within a few weeks. EndoRez (Ultradent Products. Inc, Utah, USA) is a hydrophilic urethane methacrylate resin sealer that has shown to exhibit biocompatibility ${ }^{47}$ and has the ability to penetrate dentinal tubules. ${ }^{48}$ It is used in conjunction with solid cores of resin coated GP.

Calcium silicate-based:

As sealers can be easily extruded from the root canal during obturation, there is great need for it to be accepted by the periradicular tissues. Calcium silicate-based sealers appear to be the obvious next step, given the excellent sealing properties and biocompatibility displayed by bulk calcium silicates. There are now a number of commercially available varieties such as iRoot SP (Innovative Bioceramix, Vancouver, Canada), smartpaste bio (DRFP Ltd, Stanford, UK) and MTA Fillpex (Angelus Soluções Odontológicas, Londrina, Brazil). Most are applied in a prefilled syringe and have a similar viscosity to conventional sealers. In principle, a sealer based on calcium silicate material should prove to be successful; nonetheless, caution should be taken as the materials have been modified to produce clinically workable characteristics and research on these materials remains limited at this stage.

Silicone-based:

RoekoSeal (Coltene Whaledent, Altstätten, Switzerland) is a polydimethylsiloxanebased root canal sealer. Produced in a mixing syringe, it has low viscosity to flow within the root canal system, demonstrates little shrinkage and has been developed to be biocompatible. As limited independent research has been carried out, these claims cannot be fully substantiated.

\section{Two-part semi solid core and cement obturation systems}

\section{Real Seal}

Real Seal (SybroEndo, Orange, USA) (Fig. 6) has been developed with the objective of bonding to the internal surface of the root canals and then forming a homogenous 
union with dentine in order to seal the canal. The solid core (Resilon) is presented in a form that is very similar to GP but is in fact a resinbased material. The cones or pellets consist of polyester, difunctional methacrylate resin, bioactive glass and radiopaque fillers. It is available in standardised/non-standardised cones and pellets. The Real Seal system can be used for lateral and warm vertical compaction and both components should be proprietary products for the system to work effectively. The final stages of irrigation consist of using a chelating agent such as 17\% Ethylenediaminetetraacetic acid (EDTA) followed by sterile water. Sodium hypochlorite should not be used in the final phase of irrigation as it can affect the bond strength of the system to dentine. When using a heat carrier with the Real Seal system, the temperature should not exceed $150^{\circ} \mathrm{C}$; pellet gun devices should be set between 120-160 ${ }^{\circ} \mathrm{C}$ depending on the gauge of the needle.

\section{SmartSeal}

Smartseal (Smartseal DRFP Ltd, Stamford, $\mathrm{UK}$ ) is an epoxy-amine-based resin material consisting of two components: propoint (core) and smartpastebio (cement) The master point is coated in a hydrophilic polymer, which, once hydrated swells in a lateral (not apical) fashion (Fig. 7). Used for various applications over the years, this hydrophilic polymer is similar to those employed in soft contact lenses and intraocular lens used for cataract treatment. Tapered master cones of various configurations are available including those to match a number of preparation systems; the master points should be used with smartpastebio, which is calcium silicate-based. Smartseal is in essence, a single cone technique with sealer. As solvents such as chloroform will be ineffective for removal when retreating teeth that have been obturated with Smartseal, it is recommended that removal be carried out with rotary instruments. Limited research has, as of yet, been conducted on this material.

\section{OBTURATION TECHNIQUES}

While there are many possible techniques for obturating the root canal system this article aims to focus primarily on those most commonly employed. These include:

- Lateral compaction (cold and warm)

- Vertical compaction (continuous and interrupted wave)

- Apical 'barrier'

- Thermomechanical compaction

- Carrier-based

- Single cone.

\section{Cold lateral compaction}

Cold lateral compaction is still seen as the gold standard obturation technique ${ }^{49}$ and is

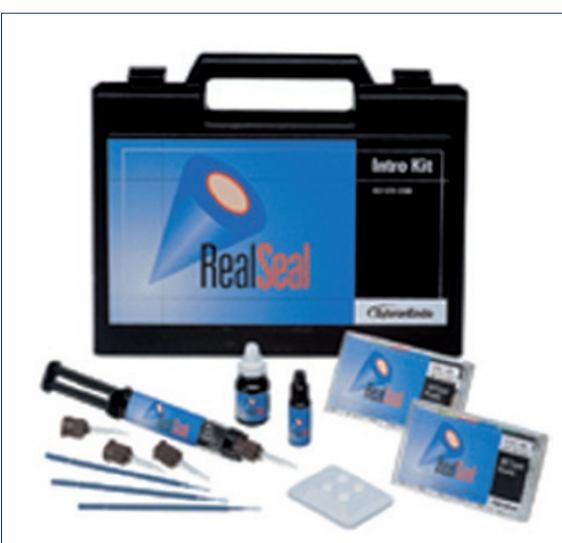

\section{Fig. 6 RealSeal}
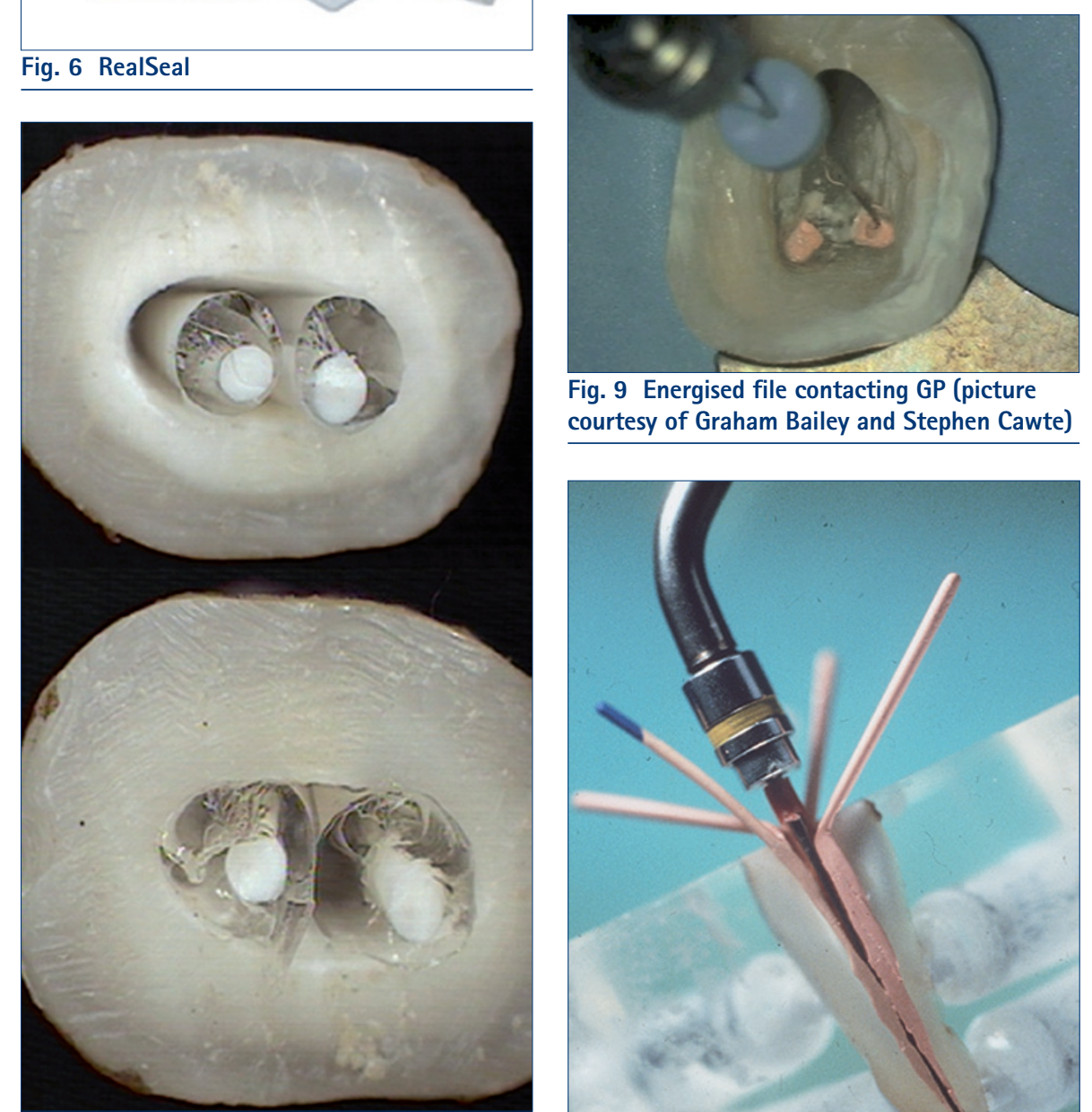

Fig. 7 Smartseal points with hydrophilic polymer swelling laterally (Please note the polymer is colourless in the image so that the expansion of the polymer is clearly visible for illustrative purposes. The coating on the Smartseal point is actually white in colour)

always the standard against which others are measured against. It is relatively easy to carry out, allows for good apical control and is cost effective. The step by step technique is described below:

- Use a spreader that can penetrate to working length (WL) without binding or being too loose

- Place a silicone stop on the spreader to mark this to $1 \mathrm{~mm}$ from the WL

- Choose a standardised ISO taper (0.02) master GP point that fits snugly at working length with 'tug back'. This
Fig. 9 Energised file contacting GP (picture courtesy of Graham Bailey and Stephen Cawte)

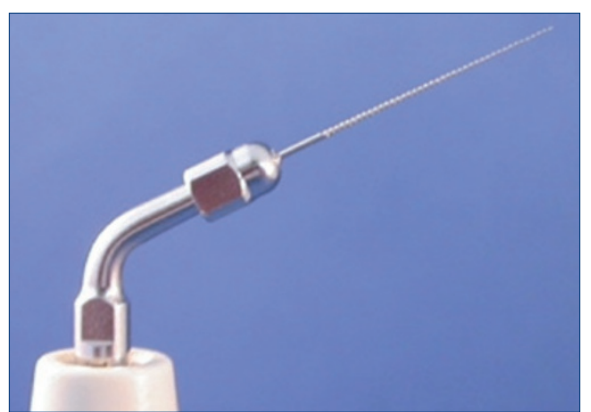

Fig. 8 File adaptor and $\mathrm{K}$ type file (picture courtesy of Graham Bailey and Stephen Cawte)

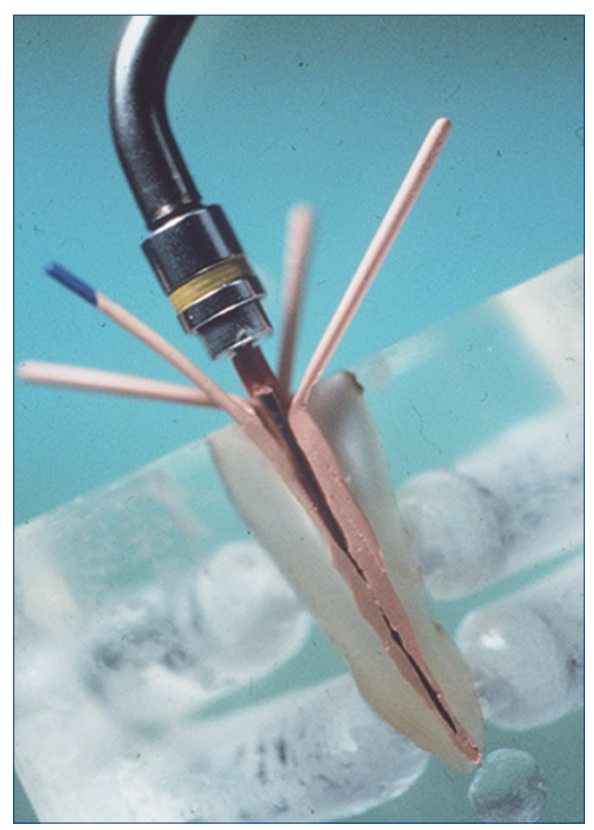

Fig. 10 Energised file making a tract to $1 \mathrm{~mm}$ from working length (picture courtesy of Graham Bailey)

may not correspond to the master apical file size

- Have approximately three accessory cones measured to $1 \mathrm{~mm}$ from the WL

- Dry the canal with paper points

- Coat the tip of the master cone with sealer and place into the canal coating the inside of the canal wall with sealer. Ensure the master GP point goes to working length

- Ease the finger spreader down to $1 \mathrm{~mm}$ from the WL

- Remove the finger spreader with a twist 


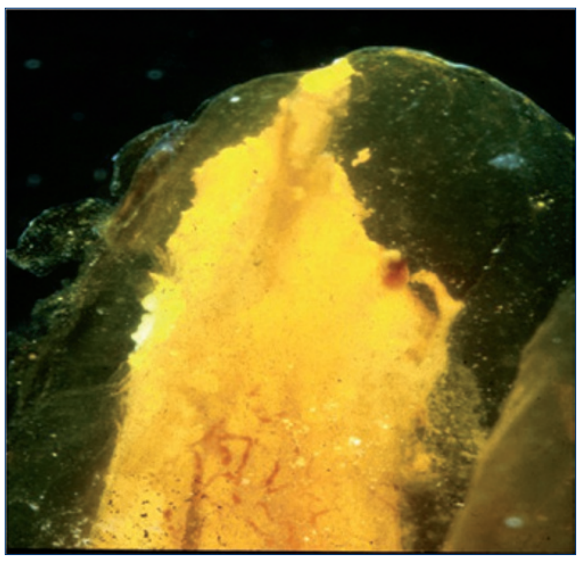

Fig. 11 Cross section of Energised spreading obturation (picture courtesy of Graham Bailey)

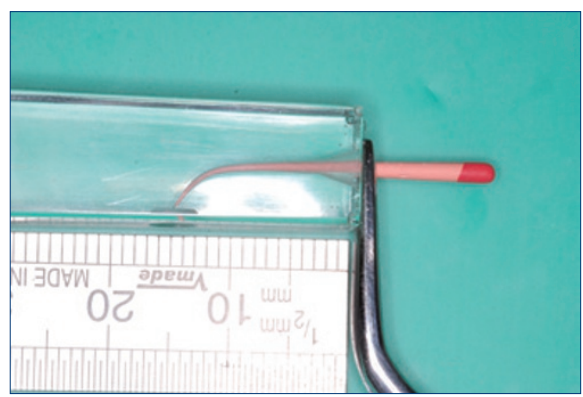

Fig. 12 Fitting Master point for warm vertical compaction

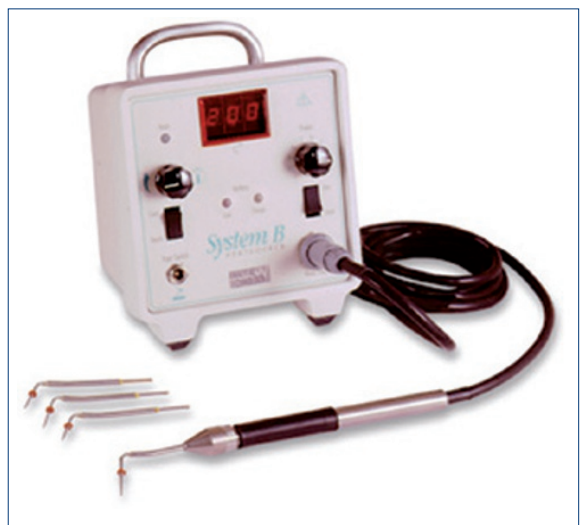

Fig. 13 System B with pluggers

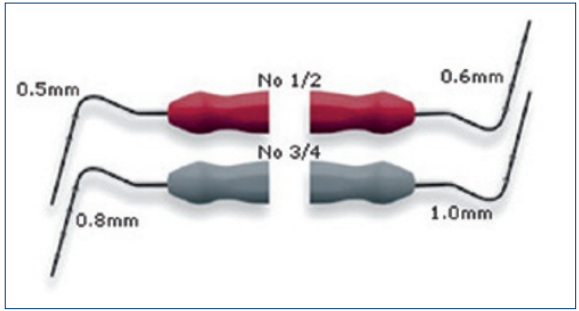

Fig. 14 Machtou pluggers sizes 1-4

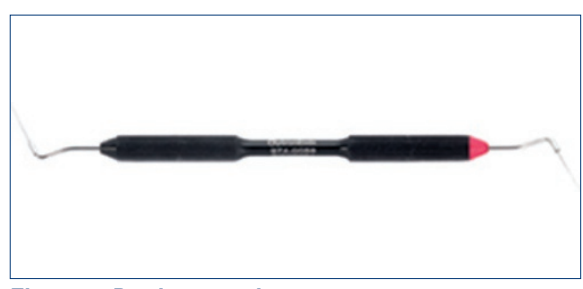

Fig. 15 Buchanan plugger and place an accessory point precisely from where the spreader was removed and ensure it penetrates to $1 \mathrm{~mm}$ from the WL. Important: use accessory cones that match your manufacturer's spreader size

- The second accessory point may not go entirely to $1 \mathrm{~mm}$ from the WL as the apical part of the canal is beginning to be filled. However, it is important to assess how far your spreader penetrates into the canal and ensure that each proceeding accessory cone reaches this same length

- After placing two to three accessory points take a mid-fill radiograph. This is carried out in place of a master GP cone radiograph. The mid fill radiograph will assess whether the master point has moved during placement of accessory points, if it has, the GP can be taken out and the apical fill repeated

- If the result is satisfactory continue to fill the rest of the canal with accessory points to just below canal orifice

- Once the obturation is complete sear the cones off at orifice level and vertically compact with a plugger.

\section{Warm lateral compaction using ultrasonics (energised spreading)}

Energised spreading is a modification of cold lateral compaction ${ }^{50}$ and follows the same protocol as listed above. A peizoelectric ultrasonic unit is required, as well as a file adaptor and a $\mathrm{k}$ type of file (Fig. 8). The ultrasonic unit is set to a higher power setting and is activated only when the file comes into contact with the GP (Fig. 9). The file is then gradually introduced into the GP and heat is generated to soften it. The file should ideally pass to $1 \mathrm{~mm}$ from the working length while making a tract in the GP (Fig. 10). A spreader is then placed into this tract to the same length, followed by a corresponding accessory point. This can be repeated two to three times. This technique has a slight advantage over cold lateral compaction, in that the thermoplasticised GP may flow into accessory anatomy (Fig. 11) and defects caused by internal resorption. It is considered a cost effective technique.

\section{Warm vertical compaction}

Originally introduced by Schilder in $1967,{ }^{51}$ modified versions of warm vertical compaction have come to be known as the continuous wave compaction technique ${ }^{52}$ and the interrupted wave compaction technique. The technique used in warm vertical compaction may make it possible for accessory apical anatomy and internal resorption defects to be filled using thermoplasticised GP. Care and attention to detail with the technique can produce excellent results. However, disadvantages include: length control of the root filling and the initial cost of the equipment. The step-by-step technique of continuous wave compaction is described in below:

\section{The continuous wave compaction technique}

\section{Downpack:}

- Fit the master cone (either nonstandardised cones or system matching cones) $0.5 \mathrm{~mm}$ from the WL in the canal until 'tug-back' is felt (Fig. 12). The cone should be tried into a wet canal and the opportunity taken to agitate the irrigant; this is done by pumping the cone in and out of the canal so as to increase the movement of the irrigant

- Select a System B plugger (SybroEndo, Orange, USA) (Fig. 13) that binds gently in the prepared canal at about 5 to $7 \mathrm{~mm}$ from the WL and mark with a silicone stop

- Coat the master cone lightly with sealer and apply to the walls of the canal. Seat the master cone

- The System B (SybroEndo, Orange, USA) (Fig. 13) heat source is best used at a temperature of $200^{\circ} \mathrm{C}$ and a power setting of ten. The touch mode seems to be considered the easiest setting to use

- Activate the touch spring while driving the heated plugger smoothly through the GP over a maximum of three seconds to 5 to $7 \mathrm{~mm}$ from the WL

- Maintain firm apical pressure for a ten second sustained push to take up any shrinkage that might occur upon cooling of the apical mass of GP

- While still maintaining apical pressure, push the touch spring again for a full second. Release the switch, pause for another full second, and then quickly withdrawn the plugger. This should remove the surplus coronal portion of GP

- After removal of the System B plugger, use a Machtou plugger (Dentsply Maillefer, Ballaigues, Switzerland) (Fig. 14) or Buchanan plugger (Fig. 15) to pack the apical portion of GP lifting any excess GP off the walls of the canal and packing it on to the apical mass.

Backfilling with thermoplasticised GP:

- Devices capable of carrying out such a backfill technique include: Obtura (SybroEndo, Orange, USA) (Fig. 16), D\&t Super beta endo (D \& L Biotech, Kyunggido, Korea) (Fig. 17) and Calamus (Dentsply Tulsa Specialities, Johnson City, USA) 
- Select a needle (various gauges) with a silicone stop that fits 5 to $7 \mathrm{~mm}$ from the WL and contacts the apical GP mass (Fig. 18)

- Lightly recoat the walls of the unfilled canal space with sealer

- Introduce the needle tip until it contacts the apical GP. Hold in place for several seconds, to allow the surface to plasticise slightly and fuse with the new GP

- Squeeze the trigger until the gun starts to back out of the canal. Maintain light resistance while letting the needle drive coronally, still keeping it embedded in the mass

- Just before orifice level, withdraw the needle and immediately apply apical pressure with a hand plugger such as Machtou plugger or a Buchanan plugger. This will compensate for cooling contraction (Fig. 19).

\section{Interrupted wave}

The interrupted wave technique is very similar to the continuous wave, with the difference being that the downpack is carried out in multiple waves rather than one continuous wave as described above. This technique is recommended for wider canals

\section{Apical fill in open apex cases}

Calcium silicates are currently the material of choice for apical fillings in immature or 'blunder bus' apices. Their aforementioned properties make them ideal candidates for preventing extrusion if handled correctly. Most calcium silicate cements are presented in a powder liquid form and are mixed to the required consistency. A number of specialised instruments have been developed to assist in the placement of these materials such as the MAP system (Produits Dentaires, Vevey, Switzerland) (Fig. 20), which enables precise placement of the material to the desired site for both orthograde and reterograde indications. When placing the material to obturate a wide root canal $(\geq 0.7 \mathrm{~mm})$ or a perforation repair the calcium silicate cement should be expelled from the device carefully at the given length and should not be packed in the same way as other conventional materials; rather, it should be delicately manipulated into place with a plugger or a large flat-ended paper point. The latter tool gives the advantage of absorbing any excess moisture. As the periradicular tissues have a spongy consistency, there will be no resistance form to pack against, so particular care must be taken. Ideally $6 \mathrm{~mm}$ apical fill should be placed, however, one must respect the future restorative needs of the tooth and the length of the pulp chamber that remains to gain retention (Figs 21a-21d). For retrograde placement, either a carrier can

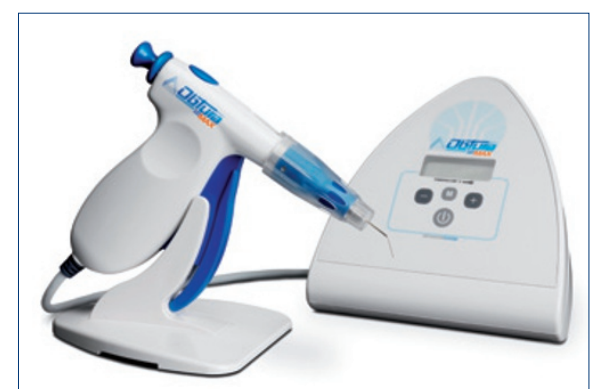

Fig. 16 Obtura III Max

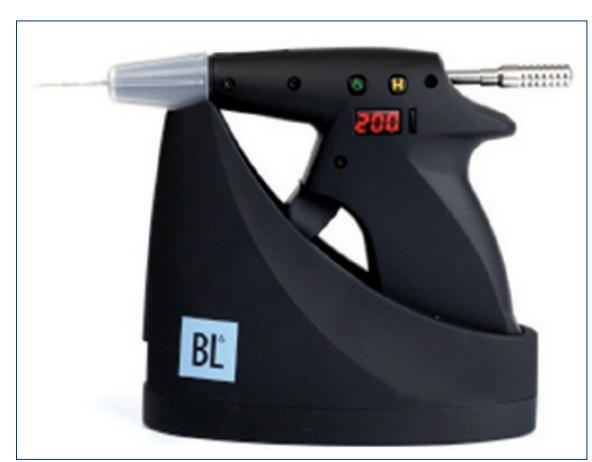

Fig. 17 DEtL SuperEndo-beta

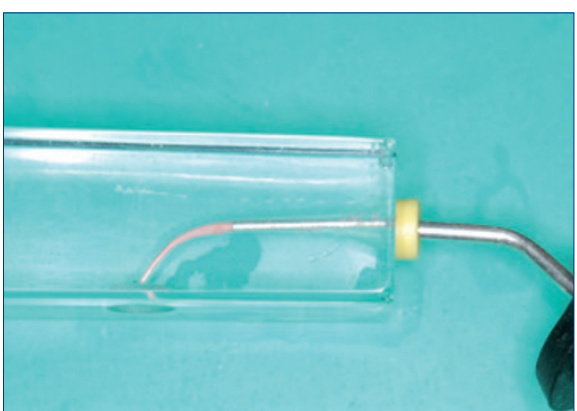

Fig. 18 Needle to deliver thermoplasticed GP in contact with downpack

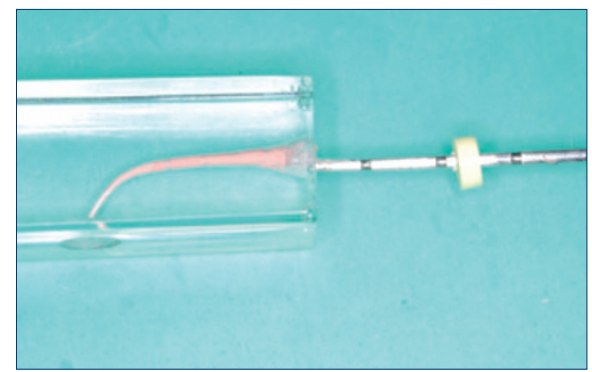

Fig. 19 Machtou plugger packing the thermoplasticised GP

be used or the material can be shaped in a Lee block (Fig. 22). The latter enables a thin column of the material to be easily picked up by an appropriate instrument and ensures that it can be placed directly in the retrograde cavity (Fig. 23).

\section{Thermomechanical compaction}

Thermomechanical compaction uses heat generated from the friction created when a reverse Hedstrom file (Fig. 24) is driven with a slow handpiece into the GP. ${ }^{53} \mathrm{~A}$ master point is fitted with a sealer and the reverse Hedstrom file

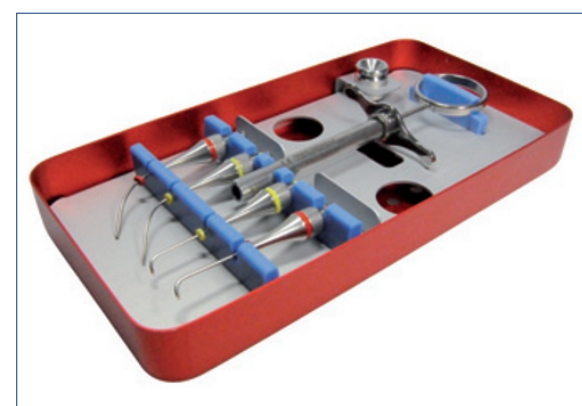

Fig. 20 MAP system

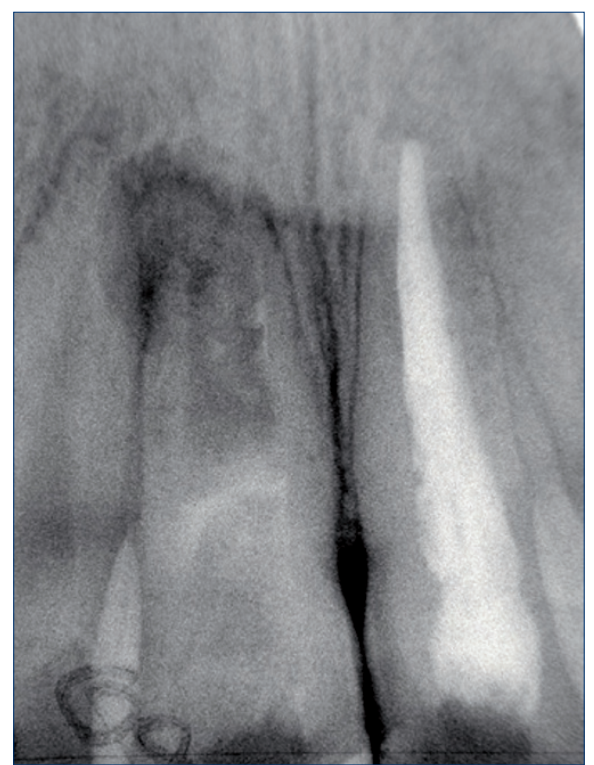

Fig. 21a Radiograph of 11 with a wide apex

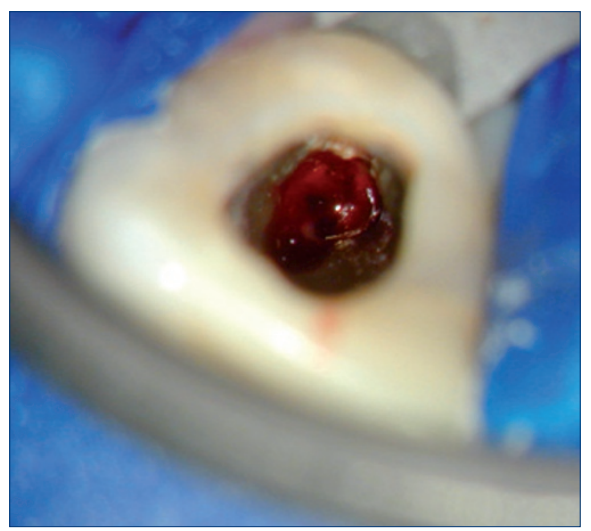

Fig. 21b Open apex viewed through operating microscope

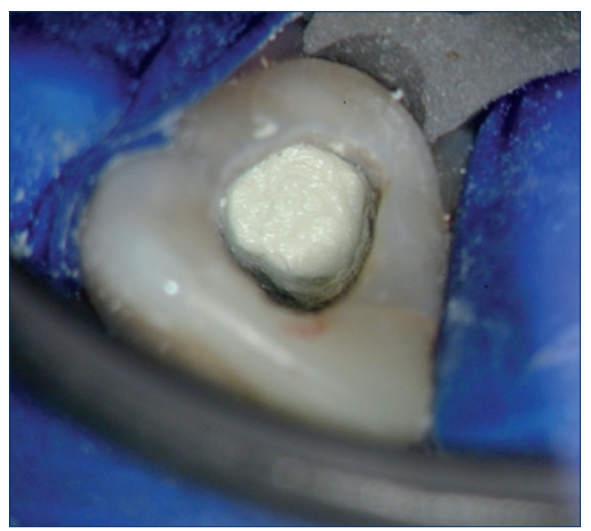

Fig. 21c MTA apical fill in place 


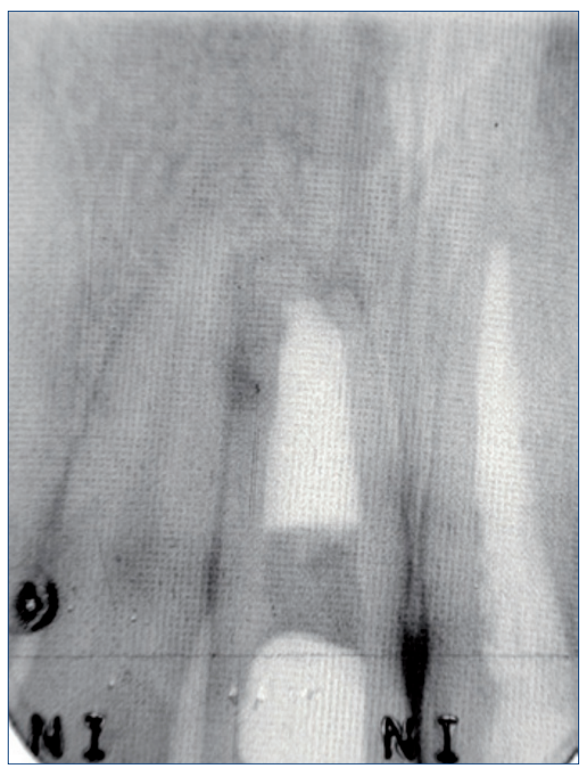

Fig. 21d Post-operative radiograph of MTA apical fill 11

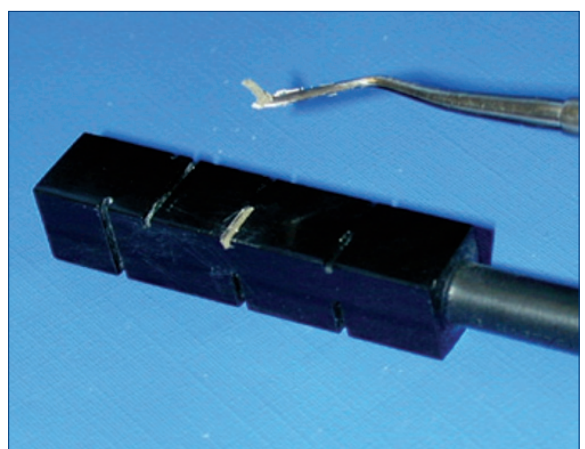

Fig. 22 MTA pellet shaped by Lee block

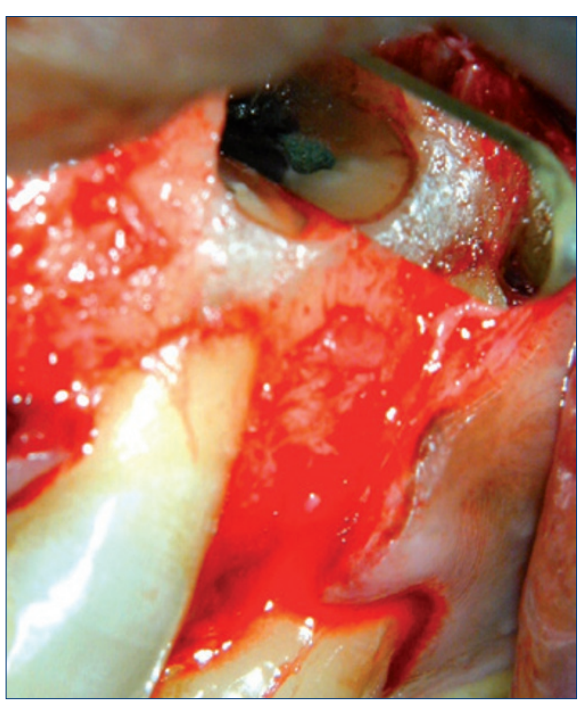

Fig. 23 MTA retrofill in apical surgery

is placed 3 to $4 \mathrm{~mm}$ from the working length. The generated heat drives the GP apically and laterally, and, eventually the file itself is driven coronally. This technique can fill irregularities and is useful for backing filling after warm vertical condensation if there are defects. This technique can cause material to be extruded from the canal and it is possible for the reverse Hedstrom to separate in the canal. The Tagger

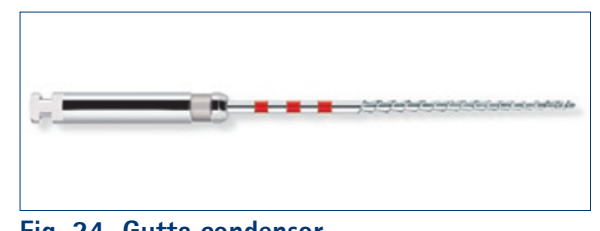

Fig. 24 Gutta condensor

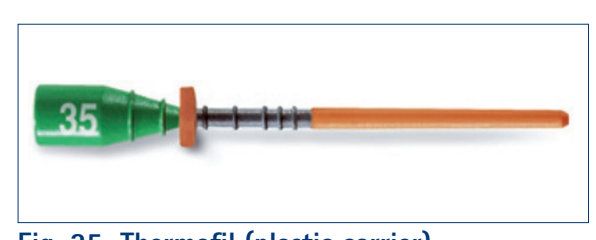

Fig. 25 Thermafil (plastic carrier)

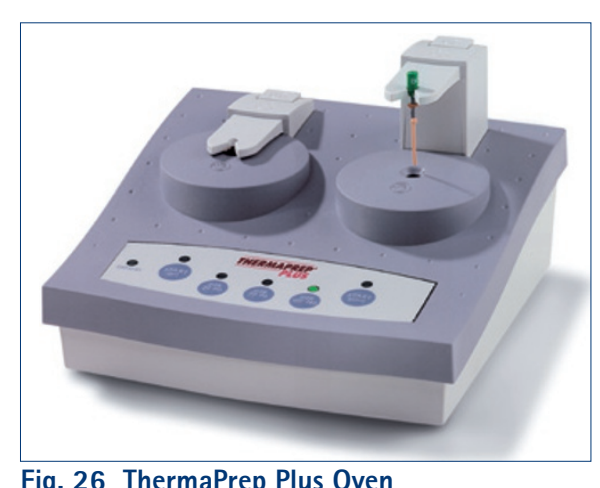

technique $^{54}$ is similar, but in the apical third/ half of the canal cold lateral condensation is used before insertion of the reverse Hedstrom file. There have been other modifications of thermomechanical compaction in which the gutta condenser is coated in flowable GP, for example Microseal (SybroEndo, Orange, USA) and then condensed. Unfortunately, despite promising results this system has now been discontinued.

\section{Carrier-based}

Carrier based techniques consist of a carrier coated in GP. Traditionally the carriers were made from stainless steel and titanium Thermafil (Dentsply Maillefer, Ballaigues, Switzerland) (Fig. 25) but are now only manufactured from plastic Thermafil (Dentsply Maillefer, Ballaigues, Switzerland). Recently, a crosslinked GP carrier Gutta Core (Dentsply Maillefer, Ballaigues, Switzerland), has been developed. This crosslinked GP carrier has the advantage of being more easily removed for post placement and for when retreatment is carried out. The technique for each of these is the same. A verifier is used to check which size carrier should be employed. The carrier is then heated in a purpose designed oven (Fig. 26) for a specified time in order to soften the outer coating of GP. The canal coated in sealer and the warmed carrier is pushed to the working length. The handle from the carrier is then removed and the coronal GP condensed vertically. There are matching carriers for systems such as Protaper, Recripoc, Waveone, etc. Although this technique is time efficient, problems can arise in the form of length control and postoperative pain.

\section{Single cone}

Using a traditional standardised single GP point and sealer technique is not recommended, as it does not provide a good three dimensional barrier from the coronal to apical aspect of the root. Smartseal is a single cone technique that was discussed earlier, which has an active property to enhance lateral filling of root canal space in order to provide a more three dimensional fill. As it is still a relatively new product there is little research evidence to determine its performance.

\section{ASSESSING OBTURATION}

\section{Clinical outcome of non-surgical and surgical cases}

Clinically and radiographically it is not possible to determine how well the root canal system has been cleaned and obturation, therefore, becomes a surrogate marker of how well it has been prepared and by inference, how well it has been cleaned. The root filling is judged by its taper, condensation and length. Aiming to provide a well condensed root filling ending just coronal to the apical foramen is desirable and moreover important for periapical health to ensure material is not extruded into the periapical tissues. A recent systematic review noted that root fillings produced without voids, and which extended to within $2 \mathrm{~mm}$ of the radiographic apex, had a significantly improved outcome. ${ }^{12}$ A short root filling could indicate that the entire length of the canal has not been adequately chemo-mechanically prepared, while a canal with extruded material could cause delayed healing or treatment failure due to inflammation ${ }^{55}$ or foreign body reaction. ${ }^{56}$

There is evidence to show that the presence and quality of the pre-existing root filling, as well as an adequate coronal seal have a positive effect on periapical health and healing following surgery. ${ }^{57}$ This further strengthens the importance of obturation in endodontic treatment even in failed cases as it may affect the success subsequent surgical treatment. The provision of a rootend filling material is also likely to increase the potential for success. ${ }^{58}$

\section{In vitro methods}

Laboratory methods to assess the 'sealability' of root canals following obturation has been traditionally tested by leakage studies. However, the validity of these studies has been questioned, with a recent editorial in the International Endodontic Journal 
warning that they must be viewed with some caution. It was found that most of these in vitro leakage studies were poorly designed..$^{5}$

\section{CONCLUSION}

Chemo-mechanical preparation of the root canal system before obturation is essential. Obturation of the root canal system to the correct length and with no voids ensures enhanced success. The coronal seal also plays an integral part in this success. No system is superior to another and case selection may be important. Recent developments have attempted to facilitate easier methods of obturating canals; however, due to the limitations of in vitro research in this area, patience is required to allow robust clinical trials to emerge.

1. Kakehashi S. The effects of surgical exposures of dental pulps in germ-free and conventiona laboratory rats. Oral Surg Oral Med Oral Patho/1965: 20: 340-349.

2. Klevant F J, Eggink C O. The effect of canal preparation on periapical disease. Int Endod J 1983; 16: $68-75$.

3. Haapasalo M, Endal U, Zandi H, Coil J M. Eradication of endodontic infection by instrumentation and irrigation solutions. Endodontic Topics 2005; 10: 77-102.

4. Ørstavik D. Materials used for root canal obturation: technical, biological and clinical testing. Endodontic Topics 2005; 12: 25-38.

5. Ray H A, Trope M. Periapical status of endodontically treated teeth in relation to the technical quality of the root filling and coronal restoration. Int Endod J 1995; 28: 12-18.

6. Sundqvist G, Figdor D. Endodontic treatment of apical periodontitis. In Ørstavik D, Pitt Ford T R (eds) Essential endodontology. Prevention and treatment of apical periodontitis. Oxford: Blackwell, 1998.

7. Bystrom A, Sundqvist G. Bacteriologic evaluation of the efficacy of mechanical root canal instrumentation in endodontic therapy. Scand J Dent Res 1981; 89: 321-328.

8. Pitt Ford T R, Rhodes J S, Pitt Ford H E. Obturation techniques. In Pitt Ford T R, Rhodes J S, Pitt Ford $\mathrm{H}$ E(eds) Endodontics: problem-solving in clinical practice. pp 121. London: Martin Dunitz, 2002.

9. Gutmann J L. Adaption of injected thermoplasticised gutta percha in the absence of the dentinal smear layer. Int Endod J 1993; 26: 87-92.

10. Ng Y L, Mann V, Gulabivala K. A prospective study of the factors affecting outcomes of nonsurgical root canal treatment: part 1: periapical health. Int Endod J 2011; 44: 583-609.

11. Torabinejad M, Ung B, Kettering J D. In vitro bacterial penetration of coronally unsealed endodontically treated teeth. J Endod 1990; 16: 566-569.

12. Ng Y L, Mann V, Rahbaran S, Lewsey J, Gulabivala K. Outcome of primary root canal treatment: systematic review of the literature- Part 2. Influence of clinical factors. Int Endod J 2007; 41: 6-31.

13. Sorensen J A, Martinoff J T. Endodontically treated teeth as abutments which discusses the incidence of tooth fracture with and without the provision of a cast restoration in endodontically treated teeth. J Prosthet Dent 1985; 53: 631-636.

14. Ng Y L, Mann V, Gulabivala K A. Prospective study of the factors affecting outcomes of non-surgical root canal treatment: part 2: tooth survival. Int Endod J 2011; 44: 610-625.

15. Saunders W P, Saunders E M. Assessment of leakage in the restored pulp chamber of endodontically treated multirooted teeth. Int Endod J 1990; 23: 28-33.

16. Pisano D M, DiFiore $P M, M c C l a n a h a n ~ S B$, Lautenschlager E P, Duncan J L. Intra-orifice sealing of gutta percha obturated root canals to prevent coronal leakage. J Endod 1998; 24: 659-662.

17. Grossman L I. Endodontic practice. Philadelphia: Lea and Febiger, 1978.

18. Friedman C E, Sandrik J L, Heuer M A, Rapp G W. Composition and physical properties of guttapercha endodontic filling materials. J Endod 1977; 8: 304-308.

19. Lee $S$ J, Monsef M, Torabinejad M. Sealing ability of a mineral trioxide aggregate for repair of lateral root perforations. J Endod 1993; 19: 541-544.

20. Torabinejad M, Parirokh M. Mineral trioxide aggregate: a comprehensive literature review-part II: leakage and biocompatibility investigations. J Endod 2010; 36: 190-202.

21. Sarkar N K, Caicedo R, Ritwik P, Moiseyeva R, Kawashima I. Physicochemical basis of the biologic properties of mineral trioxide aggregate. J Endod 2005; 31: 97-100.

22. Bozeman T B, Lemon R R, Eleazer P D. Elemental analysis of crystal precipitate from grey and white MTA. J Endod 2006; 32: 425-428.

23. Reyes-Carmona J F, Felippe M S, Felippe W T. Biomineralization ability and interaction of mineral trioxide aggregate and white portland cement with dentin in a phosphate-containing fluid. J Endod 2009; 35: 731-736.

24. Tomson P L, Grover L M, Lumley P J et al. Dissolution of bio-active dentine matrix components by mineral trioxide aggregate. J Dent 2007; 35: 636-642.

25. Tomson P L, Lumley P J, Alexander M Y, Smith A J, Cooper P R. Hepatocyte growth factor is sequestered in dentine matrix and promotes regeneration-associated events in dental pulp cells. Cytokine 2013; 61: 622-629.

26. Oliveira M G, Xavier C B, Demarco F F et al. Comparative chemical study of MTA and Portland cements. Braz Dent J 2007; 18: 3-7.

27. Camilleri J, Kralj P, Veber M, Sinagra E. Characterization and analyses of acid-extractable and leached trace elements in dental cements. Int Endod J 2012: 45: 737-743.

28. Song J S, Mante F K, Romanow W J, Kim S. Chemical analysis of powder and set forms of Portland cement, grey ProRoot MTA, white ProRoot MTA, and grey MTA-Angelus. Oral Surg Oral Med Oral Pathol Oral Radiol Endod 2006; 102: 809-815.

29. Santos A D, Araujo E B, Yukimitu K, Barbosa J C, Moraes J C. Setting time and thermal expansion of two endodontic cements. Oral Surg Oral Med Oral Pathol Oral Radiol Endod 2008; 106: e77-79.

30. Duarte M A, De Oliveira Demarchi A C, Yamashita J C, Kuga M C, De Campos Fraga S. Arsenic release provided by MTA and Portland cement. Oral Surg Oral Med Oral Pathol Oral Radiol Endod 2005; 99: 648-650.

31. De-Deus G, de Souza M C, Sergio Fidel R A et al. Negligible expression of arsenic in some commercially available brands of Portland cement and mineral trioxide aggregate. J Endod 2009; 35: 887-890.

32. Park J W, Hong S H, Kim J H, Lee S J, Shin S J. X-Ray diffraction analysis of white ProRoot M T A, Diadent BioAggregate. Oral Surg Oral Med Oral Pathol Oral Radiol Endod 2010; 109: 155-158.

33. Richard G. On Biodentine, a new standard in endodontics and restorative dentistry: from scientific concept to the clinical use. Personal communication, 2010.

34. Ørstavik D, Kerekes K, Eriksen H M. Clinical performance of three endodontic sealers. Endod Dent Traumatol 1987; 3: 178-186.

35. Grossman L I. An improved root canal cement. J Am Dent Assoc 1958; 56: 381-385.

36. Al-Khatib Z Z, Baum R H, Morse D R, Yesilsoy C, Bhambhani S, Furst M L. The antimicrobial effect of various endodontic sealers. Oral Surg Oral Med Oral Pathol 1990; 20: 784-790.
37. Allan N A, Walton R E, Schaffer M. Setting times for endodontic sealers under clinical usage and in vitro conditions. J Endod 2001; 27: 421-423.

38. Langeland K. Root canal sealants and pastes. Dent Clin North Am 1974; 18: 309-327.

39. Augsburger R A, Peters D D. Radiographic evaluation of extruded obturation materials. J Endod 1990; 16: 492-497.

40. Kazemi R B, Safavi K E, Spångberg L S. Dimensional changes of endodontic sealers. Oral Surg Oral Med Oral Pathol 1993; 76: 766-771.

41. Peters D D. Two year in vitro solubility evaluation of four gutta percha sealer obturation techniques. J Endod 1986; 12: 139-145.

42. Desai $S$, Chandler N. Calcium hydroxide based root canal sealers: a review. J Endod 2009; 35: 475-480.

43. Huang F M, Tai K W, Chou M Y, Chang Y C. Cytotoxicity of resin, zinc oxide-eugenol and calcium hydroxide-based root canal sealers on human periodontal ligament cells and permanent V79 cells. Int Endod J 2002; 35: 153-158.

44. Weiger $R$, Heuchert $T$, Hahn R, Lost $C$. Adhesion of a glass ionomer cement to human radicular dentin. Endod Dent Traumatol 1995; 11: 214-221.

45. Chadha R, Taneja S, Kumar M, Gupta S. An in vitro comparative evaluation of depth of tubular penetration of three resin-based root canal sealers. J Conserv Dent 2012; 15: 18-21.

46. McMichen F R, Pearson G, Rahbaran S, Gulabivala. A comparative study of selected physical properties of five root-canal sealers. Int Endod J 2003; 36: 629-636.

47. Zmener 0 . Tissue response to a new methacrylatebased root canal sealer: preliminary observations in the subcutaneous connective tissue of rats. J Endod 2004: 30: 348-351.

48. Kardon B P, Kuttler S, Hardigan P, Dorn S O. An in vitro evaluation of the sealing ability of a new root canal obturation system. J Endod 2003; 29: 658-661.

49. Ansari B B, Umer F, Khan F R clinical trial of cold lateral compaction with Obtura II technique in root canal obturation J Conserv Dent 2012; 15: 156-160.

50. Bailey G C, Ng Y L, Cunnington S A, Barber $P$, Gulabivala K, Setchell D J. Root canal obturation by ultrasonic condensation of gutta-percha. Part II: an in vitro investigation of the quality of obturation. Int Endod J 2004; 37: 694-698.

51. Schilder H. Filling root canals in three dimensions.1967. J Endod 2006: 32: 281-290.

52. Buchanan L S. The continuous wave of obturation technique: 'centered' condensation of warm gutta percha in 12 seconds. Dent Today 1996; 15: 60-62, 64-67.

53. McSpadden J T. Presentation to the meeting of American Association of Endodontists. Atlanta, Georgia: 1979.

54. Tagger M, Tamse A, Katz A, Korzen B H. Evaluation of the apical seal produced by a hybrid root canal filling method, combining lateral condensation and thermatic compaction. J Endod 1984; 10: 299-303.

55. Sjögren $U$, Sundqvist $G$, Nair $P$ N. Tissue reaction to gutta-percha of various sizes when implanted subcutaneously in guinea pigs. Eur J Oral Sci 1995: 103: 313-321.

56. Nair P N, Sjögren U, Krey G, Sundqvist G. Therapyresistant foreign body giant cell granuloma at the periapex of a root-filled human tooth. J Endod 1990; 16: 589-595.

57. Rahbaran S, Gilthorpe M S, Harrison S D, Gulabivala K. Comparison of clinical outcome of periapical surgery in endodontic and oral surgery units of a teaching dental hospital: a retrospective study. Oral Surg Oral Med Oral Pathol Oral Radiol Endod 2001; 91: 700-709.

58. Gutmann J L, Pitt Ford T R. Management of the resected root end: a clinical review. Int Endod J 1993: 233: 272-283.

59. De Deus G. Research that matters - root canal filling and leakage studies. Int Endod J 2012; 45: 1063-1064. 